Shi Zheng, Pei Xu, Zhigang Wang

\title{
Are Nutrition Labels Useful for the Purchase of a Familiar Food? Evidence from Chinese Consumers' Purchase of Rice
}

(C) Higher Education Press and Springer-Verlag 2011

\begin{abstract}
Nutrition labeling has been accepted by Chinese consumers as an information source to learn about food quality and safety. This paper uses Chinese consumers' rice purchase as an example to study how consumers use food nutrition labels to make purchase decision of a familiar food product. The goal is to understand how consumers seek information from the labels to make purchase when extensive experience with the food has been developed. Survey data from 400 random respondents in Beijing were analyzed using an empirical framework and a Mont Carlo integral econometrics model. We find that more than $50 \%$ of the consumers in Beijing have heard of food nutrition labels in general, $36.50 \%$ carefully use label information even if they are familiar with the food, and nearly $70 \%$ consider mandatory food nutrition labels as beneficial. Those who are more knowledgeable about rice nutrition labels are more likely to use the labels when purchasing rice, no matter how familiar they are with the product. Frequent users of nutrition labels are more likely to consider food mandatory nutrition labels as beneficial. This study suggests that consumers
\end{abstract}

Received November 27, 2010

Shi Zheng

School of Business, Renmin University of China, Beijing 100872, China

E-mail: zhengshi1974@ruc.edu.cn

Pei Xu

Jordan College of Agricultural Science and Technology, California State University, Fresno, CA 93740, USA

E-mail: cathyxupei@hotmail.com

Zhigang Wang $(\bowtie)$

School of Agricultural Economics and Rural Development, Renmin University of China, Beijing 100872, China

E-mail: ohshigo@yahoo.com.cn 
still use the label information to reassure the quality and safety of food despite a history of consumption.

Keywords nutrition label, consumer consumption behavior, food perception, consumer behavior

\section{Introduction}

The use of labeling information is believed to be much related to the purchase of new products (Mareau, Markman and Lehmann, 2001; Zhao, Hoeffier and Dahl, 2009). With the consumption of a familiar food product, do consumers still pay significant attention to information provided on the nutrition labels? Reading information on the label takes time, and for many consumers, understanding the label is challenging. Therefore, the cost of information search could be high but the perceived benefits could be low. Under this situation, do consumers ignore the nutrition labels and just use their experience to make purchase decisions, or do they still use the labels? If consumers do use labels, marketers could have a chance to influence purchase by designing the information provided in the labels. If not, the reasons may interest marketers to help them develop alternative marketing plans to motivate purchase.

In the case of Chinese consumers' purchase of rice, with the improvement of living standard and health awareness, more attention has focused on the issue of rice quality and safety. In general, food safety concerns have become more significant after frequent food safety scandals exposed in China, including the most recent melamine-milk scandal in 2008, which has caused serious kidney problems of about 294000 children (Zhou, 2009). Therefore, Chinese consumers tend to pay more attention to the safety and nutritional contents of the food they purchase.

Adopted by many countries and areas, nutrition labels have been effectively used to measure food quality and protect consumers' health, and are perceived by the public as an important information signal which transfers nutritional composition, nutritional nature and nutritional efficacy of the food. According to the Codex Alimentarius Commission (CAC), there are two components in nutrition labels: nutrition facts and nutrition claims. In most countries and regions, the former should contain energy, protein, fat and carbohydrates. In some countries, the labels for unsaturated fatty acid, cholesterol, dietary fiber, sodium and other elements are also required. The latter presents the nutritional nature of the commodity, including the claim of nutrients content, content comparison, and the physiological function and health.

In the 1940s, the first nutritional label appeared in Great Britain, which 
presented information about an excellent source of vitamin C. Afterwards, countries worldwide started to develop the standard of daily intake of nutrients and require nutrients content of food in the labels. The CAC has set up a series of guidance and principles for nutrition label and an increased number of countries have enacted related laws and regulations since 1985.

Nutrition labels first appeared in China in the early 1990s. Although the Chinese government required food labels for special nutrient GB13432, which focused on baby food, fortified food, and nutrient adjusted food, it only started to require other labeling since 1992. By then, adding nutrition labels or not is still voluntarily for most food products. There were many problems associated with food labeling including confusing expressions, inaccurate nutrition claims, and non-standardized labeling language, which have caused serious misunderstandings by consumers. China fell far behind developed countries in formalizing nutrition labels in the 1990s.

In recent years, nutrition labels have attracted growing attention among consumers. There are three main reasons behind this new trend. First, unhealthy diet has become a threat to public health. Second, the problem of low food quality has threatened the health of many consumers. Third, exported food was frequently returned or detained by the import countries because of unclear nutrition labels. Following international institutions of food nutrition labels, the Ministry of Public Health of China enacted a new food nutrition labeling management practice, effective from May $1^{\text {st }}, 2008$. This practice standardizes the content and format of nutrition labels, and requires all packed food to comply with the regulations. From then on, nutrition labels have become mandatory instead of voluntary in China.

Chinese scholars have conducted research on nutrition labeling, however, academic analysis using quantitative and qualitative methods to study consumers' perception, acceptance and perceived benefits of nutrition labels, and purchasing behaviors is very limited. Based on a survey collected from about 400 consumers in Beijing in February 2008, we studied Chinese consumers' perception of nutrition labels when they purchase rice, a main staple in the Chinese diet. We examined whether Chinese consumers use the nutrition labels to make purchase decisions and how they believe they could benefit from a mandatory rice nutrition label.

\section{Literature Review}

Consumers' purchase intention is well examined in the literature (Ippolito et al., 1990; Gila et al., 2000; Nayga, 2000; Sedjo and Swallow, 2002; Soregarol et al., 2003; Cranfield and Magnusson, 2003; Matsumoto et al., 2004; Wu and Fu 2007; Yang and Wang 2010). A number of studies have investigated the effect of 
nutrition labels on consumption behaviors (Bush et al., 1999; Kim et al.. 2001; Piedra et al., 1996; Teisl et al., 2003). In particular, Gracia et al. (2007) suggested that the consumers who encountered health problems can better understand nutrition labels and thus can make better use of these labels. They also concluded that mandatory nutrition label is perceived as beneficial. Barreiro et al. (2008) highlighted the positive influence of nutrition labels and pointed out that consumers have obtained more nutrition and health information from the labels.

A great amount of research has been conducted to understand the credibility of labeling and its impact on consumer choices about genetically modified (GM) food (Siegrist, 2000; Roe and Teisl, 2007). For example, Roe and Teisl's study suggested that providing contact information of the certification agency is one way to enhance the credibility of a GM label.

Perceived benefits of nutrition labels are used to measure the effectiveness of labels. Wang et al. (1995) examined what consumers could gain from nutrition labels as a transferring channel of nutritional information. Nayga Jr. (1997) conducted a demographic analysis to analyze the influence of food nutrition on physical health and the importance of nutrition labels. Teisl et al. (2003) evaluated the welfare influence of the information extracted from the nutrition labels, which indicates that the value of information is high compared to the costs of disease prevention. Zeng et al. (2008) explored consumers' willingness to pay for labeled food and their perceived benefits of the safety of moon cake addictive.

In summary, the majority of the studies on nutrition certification and labels concentrate on consumers' perception, purchasing behavior and perceived benefits. Many studies have concluded that nutrition message contained in labels have significant impacts on consumer perceptions and thus greatly affect the successfulness of a product in the marketplace. The adoption of food labeling could potentially reshape the food industry as labels change consumer purchase intent. The effect of nutrition information on consumer responses to food has important public policy and market implications in China as well. This is especially important when promoting a more strict food labeling system in China. However, little has been done on this topic and this paper aims to fill in the research gap.

\section{Conceptual Framework and Research Design}

Consumers' utility of food is influenced not only by food quantity $(Q)$, but also by food attributes $(Z)$, determined by the information $(K)$ obtained from the nutrition labels. Accordingly, consumers' utility function is presented as:

$$
U=U(Q(Z(K))) \text {. }
$$


A combination of utility maximization function and consumers' budget constraint determines the demand function, which is affected by food price, income of consumers, information and other factors. This is typically defined as an indirect test of preference (Chang and Kinnucan, 1991). However, it fails to fully describe how consumers obtain and process the information contained in nutrition labels, and how nutrition labels in turn influence consumer purchasing decisions.

It is a successive procedure that consumers gain information from nutrition labels, integrate it with their own evaluations of food, and generate a new consumption concept. On the basis of the new concept, consumers form a new attitude towards the products and this attitude will influence their purchase intention and decisions. In this framework, the attitude of consumers is affected by their perceptions, as suggested by Swartz and Strand (1981).

$$
\text { Pr efer }=f_{2}(D, \text { Aware }) \text {. }
$$

Kinnucan and Venkateswaran (1990) presented an empirical model with eight equations based on the Enger model, in their effort to evaluate consumers' perception, concept, attitude and purchasing behavior. According to this method, they assumed that consumers' perceptions are determined by the characteristics of nutrition labels $(D)$.

$$
\text { Aware }=f_{1}(D) \text {. }
$$

Perception is formed based on information acquired $(K)$. If consumers understand the nutrition labels, then the information may be significant in changing their buying decision. Therefore, it is presumed that consumers' characteristics and perception change individual buying decision. Perceived benefits of purchasing can affect consumers' utility function. If consumers feel that they can benefit from nutrition labels, they would recognize the welfare associated with purchasing. Hence, utility can be affected by consumers' purchasing behavior.

$$
\text { Benefit }=f_{3}(D, \text { Pr efer }) .
$$

\section{Data and Descriptive Statistics}

Data used in the research were collected from a random survey of rice consumers in Beijing in February 2008. The questionnaire consists of three sections. The first section investigates consumers' individual, social and statistical characteristics, including gender, age, marital status, work nature, educational experience, current address, age distribution of families, average monthly expenditure on food, self-evaluated health status, the relationship between health and diet. The second section asks questions about the frequency of rice purchase, 
and considerations of rice purchase (price, freshness, nutrition, flavor, quality and safety). The third section collects information about nutrition labels of rice, including purchasing channels, the reason for choosing a certain purchasing channel, the perception of nutrition labels, the usage of the information supplied by nutrition labels and whether it is beneficial.

In total, 480 questionnaires were collected from Chaoyang District, Haidian District, Chongwen District and Dongcheng District in Beijing, among which 400 questionnaires were valid. The invalid questionnaires were eliminated because of missing information on key questions such as gender, marital status and purchase intention.

Table 1 lists descriptive characteristics of consumers. The ratio of male to female surveyed was approximately 1 to $1.93 .5 \%$ of the respondents were below 49 years old. With regard to education experience, more than half of the consumers graduated from college and a quarter graduated from junior or senior middle school. 19 respondents had an education of graduate degree or above and 58 had a low education of elementary school or below, which accounted for $14.5 \%$ of the sample. $55 \%$ of the respondents worked at enterprises of different types, followed by respondents who worked for public institution, government, and freelance business, and 5\% were migrant workers. A wide variety of occupations in the survey guaranteed representativeness of the sample. About two thirds of the respondents $(275,68.75 \%)$ lived in the central districts of Beijing, and the rest lived in suburbs. About half of respondents had a family size of 2 people $(188,47.00 \%), 40.75 \%$, a family of 3 people, $6.75 \%$, a family of 4 people, and $5.50 \%$ of the respondents were single. About $80 \%$ of respondents spent $142.85-214.14$ or $214.28-285.57$ USD in food consumption monthly. The ratios of respondents with monthly food expenditure of 71.42-142.71 (20), $285.71-357(35), 357.14-428.43$ or above 428.57 (8) were relatively small (exchange rate: $1 \mathrm{USD}=7$ yuan, approximately).

Table 1 Descriptive Statistics of Surveyed Consumers' Demographic Characteristics

\begin{tabular}{llcc}
\hline Statistical Indicator & Category & No. of respondent & Proportion (\%) \\
\hline Gender & Male & 196 & 49.00 \\
& Female & 204 & 51.00 \\
Age & $<29$ & 180 & 45.00 \\
& $30-49$ & 194 & 48.50 \\
\multirow{2}{*}{ Educational experience } & Primary school or below & 26 & 6.50 \\
& $>50$ & 58 & 14.50 \\
& Junior and senior middle school & 105 & 26.25 \\
& College \& undergraduate & 218 & 54.50 \\
\hline
\end{tabular}

(To be continued) 


\begin{tabular}{llcc} 
& & & $($ Continued $)$ \\
\hline Statistical Indicator & Category & No. of respondent & Proportion (\%) \\
\hline \multirow{3}{*}{ Work nature } & Graduate school or above & 19 & 4.75 \\
& Povernment & 56 & 14.00 \\
& Eublic institution & 65 & 16.25 \\
& Self-supporting business & 220 & 55.00 \\
Freelance & 0 & 0.00 \\
& Student & 27 & 6.75 \\
Inoccupation & 0 & 0.00 \\
Purrent address & Peasant worker & 12 & 3.00 \\
Family size & Inside the city & 20 & 5.00 \\
& Outside the city & 275 & 68.75 \\
& 1 & 125 & 31.25 \\
& 2 & 22 & 5.50 \\
Average expenditure on food & $>71.42$ & 188 & 47.00 \\
(USD/month) & 3 & 163 & 40.75 \\
& $>41.42-142.71$ & 27 & 6.75 \\
& $142.85-214.14$ & 0 & 0.00 \\
& $214.28-285.57$ & 20 & 5.00 \\
& $285.71-357$ & 136 & 34.00 \\
& $357.14-428.43$ & 35 & 46.75 \\
& $>428.57$ & 14.57 & 2.00 \\
\hline
\end{tabular}

Nearly half of the respondents claimed that their health status is normal (48.75\%). Respondents in excellent health status (59) and good health status (93) accounted for $14.75 \%$ and $23.25 \%$, respectively. Fifteen respondents evaluated their health status as bad or very bad, accounting for $13.25 \%$ of the sample. Seventy percent of the respondents felt high or very high time pressure, while only less than one third of the respondents felt low or very low time pressure. Regarding physical exercises, about $70 \%$ of the respondents took exercises occasionally (272), $24.50 \%$ often took exercises (98) and $7.50 \%$ never (30). Although most of the respondents had very limited time to take exercises because of high time pressure, the majority still insisted on spending time on exercises, suggesting that consumers' health awareness has been enhanced. Finally, more than $80 \%$ of the respondents (339) claimed that health has good or normal relation with diet and only $15.25 \%$ of the respondents thought these two are 
irrelevant with each other. It was shown that most consumers were aware of food quality and safety issues and the connection to their own health and welfare.

Table 2 Descriptive Statistics of Consumers' Health Attitude

\begin{tabular}{|c|c|c|c|}
\hline Statistical indicator & Category & No. of respondent & Proportion (\%) \\
\hline \multirow[t]{5}{*}{ Self-evaluated health status } & Excellent & 59 & 14.75 \\
\hline & Good & 93 & 23.25 \\
\hline & Normal & 195 & 48.75 \\
\hline & $\mathrm{Bad}$ & 38 & 9.50 \\
\hline & Very bad & 15 & 3.75 \\
\hline \multirow[t]{4}{*}{ Time pressure } & Very high & 112 & 28.00 \\
\hline & High & 170 & 42.50 \\
\hline & Low & 22 & 5.50 \\
\hline & Very low & 96 & 24.00 \\
\hline \multirow[t]{3}{*}{ Physical exercises } & Often & 98 & 24.50 \\
\hline & Sometimes & 272 & 68.00 \\
\hline & Never & 30 & 7.50 \\
\hline \multirow[t]{3}{*}{$\begin{array}{l}\text { The relationship between } \\
\text { health and diet }\end{array}$} & Strong & 100 & 25.00 \\
\hline & Normal & 239 & 59.75 \\
\hline & Irrelevant & 61 & 15.25 \\
\hline
\end{tabular}

Table 3 presents the influential factors of consumers' rice purchase. About $70 \%$ of the respondents (283) purchased rice once or twice per week, $26.25 \%$ once or twice per month (105) and only $3 \% 3$ or 4 times a week. This shows that most Beijing consumers do not purchase a large amount of food at one time but choose to purchase frequently instead, because of their considerations of expatriation, storage, and convenient access to supermarket. Among factors affecting purchase, price is the primary factor $(260,65 \%)$, followed by nutrition $(36,9 \%)$, freshness $(48,12 \%)$, quality and safety $(32,8 \%)$, brand $(10,2.50 \%)$ and other factors including convenience of processing, flavor preference, pack, clarity, appearance and fineness, and production place (14, 3.50\%). Most respondents considered recommendations from relatives and friends when making purchases $(108,27.00 \%)$. The appearance of rice $(220,55 \%)$ is also a deterministic factor. Other factors do not play a significant role.

Regarding the impact of information on rice purchase, about half of respondents considered quantity $(40 \%)$ as the most important factor. Over two thirds of the respondents have paid extensive or strong attention to price, indicating that price plays an important role in rice purchase. Quality and safety 
Table 3 Influencing Factors on Purchase of Rice

\begin{tabular}{|c|c|c|c|}
\hline Statistical indicator & Category & No. of observations & Proportion (\%) \\
\hline \multirow[t]{3}{*}{$\begin{array}{l}\text { Family's frequency of rice } \\
\text { purchase }\end{array}$} & 3 or 4 times per week & 12 & 3.00 \\
\hline & 1 or 2 times per week & 283 & 70.75 \\
\hline & 1 or 2 times per month & 105 & 26.25 \\
\hline \multirow[t]{6}{*}{ Considerations of rice purchase } & Price & 260 & 65.00 \\
\hline & Nutrition & 36 & 9.00 \\
\hline & Freshness & 48 & 12.00 \\
\hline & Quality and safety & 32 & 8.00 \\
\hline & Brand & 10 & 2.50 \\
\hline & Others & 14 & 3.50 \\
\hline \multirow[t]{6}{*}{ Reasons for rice selection } & $\begin{array}{l}\text { Recommendations from } \\
\text { relatives and friends }\end{array}$ & 108 & 27.00 \\
\hline & $\begin{array}{l}\text { Impressions after having } \\
\text { a look at the products }\end{array}$ & 220 & 55.00 \\
\hline & $\begin{array}{l}\text { Recommendations from } \\
\text { sellers }\end{array}$ & 12 & 3.00 \\
\hline & Others' purchase & 14 & 3.50 \\
\hline & $\begin{array}{l}\text { Advertisement } \\
\text { promotions }\end{array}$ & 6 & 1.50 \\
\hline & Trust in manufacturers & 40 & 10.00 \\
\hline
\end{tabular}

Table 4 Concern about Information in Rice Purchase

\begin{tabular}{lcccccc}
\hline Concern & Quantity (\%) & Price (\%) & $\begin{array}{l}\text { Quality and } \\
\text { safety (\%) }\end{array}$ & $\begin{array}{l}\text { Guarantee } \\
\text { period (\%) }\end{array}$ & $\begin{array}{l}\text { Nutritional } \\
\text { composition } \\
(\%)\end{array}$ & $\begin{array}{l}\text { Information } \\
\text { of labels (\%) }\end{array}$ \\
\hline Extensive & 13.50 & 25.25 & 48.25 & 24.50 & 33.25 & 2.75 \\
Strong & 24.50 & 43.00 & 24.25 & 46.75 & 36.75 & 4.25 \\
Normal & 46.75 & 16.75 & 20.25 & 19.50 & 23.50 & 14.50 \\
Weak & 8.25 & 12.00 & 6.25 & 3.75 & 4.25 & 48.25 \\
Very weak & 7.00 & 3.00 & 1.00 & 5.50 & 2.25 & 30.25 \\
\hline
\end{tabular}

Table 5 Consumers' Information Demand for Nutrition Labels of Rice

\begin{tabular}{llcl}
\hline Statistical indicator & Category & No. of respondent & Proportion (\%) \\
\hline Channel of purchasing rice & Supermarket & 300 & 75.00 \\
& Wet market & 52 & 13.00 \\
& Fixed retail store & 44 & 11.00 \\
& Others & 4 & 1.00 \\
\hline
\end{tabular}

(To be continued) 
(Continued)

\begin{tabular}{|c|c|c|c|}
\hline Statistical indicator & Category & No. of respondent & Proportion (\%) \\
\hline \multirow[t]{2}{*}{$\begin{array}{l}\text { Whether have heard about food nutrition } \\
\text { labeling management practice }\end{array}$} & Yes & 34 & 8.50 \\
\hline & No & 366 & 91.50 \\
\hline \multirow[t]{5}{*}{ Understand nutrition labels } & Excellent & 56 & 14.00 \\
\hline & Good & 90 & 22.50 \\
\hline & Normal & 62 & 15.50 \\
\hline & Bad & 120 & 30.00 \\
\hline & No & 72 & 18.00 \\
\hline \multirow[t]{5}{*}{$\begin{array}{l}\text { Number of messages in nutrition labels } \\
\text { accepted by consumers }\end{array}$} & 3 & 160 & 40.00 \\
\hline & 4 & 72 & 18.00 \\
\hline & 5 & 84 & 21.00 \\
\hline & 6 & 48 & 12.00 \\
\hline & $>7$ & 36 & 9.00 \\
\hline \multirow[t]{3}{*}{$\begin{array}{l}\text { Whether looking through the information } \\
\text { in nutrition labels when selecting food }\end{array}$} & Often & 146 & 36.50 \\
\hline & Sometimes & 182 & 45.50 \\
\hline & Never & 72 & 18.00 \\
\hline \multirow[t]{2}{*}{$\begin{array}{l}\text { Whether it is beneficial to implement } \\
\text { mandatory nutrition labels }\end{array}$} & Yes & 277 & 69.25 \\
\hline & No & 123 & 30.75 \\
\hline
\end{tabular}

are also key influential factors on purchasing decisions (70\%). About $71 \%$ of the respondents were extensively or strongly concerned about the expatriation date and nutrition of rice. Furthermore, respondents were not greatly concerned about information from labels and nearly $80 \%$ of the respondents stated that they do not consider information from labels when making purchases. The main reason is that the label of rice products usually contains more than sufficient information, making it difficult to understand. To sum up, our respondents paid most of their attention to price, quality and safety, expiration date and nutritional composition of rice when making purchase decisions.

Concerning where to purchase rice, three quarters of the respondents bought rice at supermarkets, wet markets was the second popular place $(13 \%)$ and followed by fixed retail stores (11\%). These findings suggest that Chinese consumers trust supermarket most and consider supermarkets as convenient for food purchases. When respondents were asked about whether they have heard of Food Nutrition Labeling Management Practice, over 90\% said no. When asked about how familiar they are with the nutrition labels, 146 respondents $(36.50 \%)$ 
said they have excellent and good understandings about nutrition labels, and 192 respondents $(48 \%)$ had little understanding. A great majority of them (91\%) could not accept more than 6 messages in the nutrition labels. About two thirds of respondents $(254,63.50 \%)$ read the nutrition labels only occasionally or never, indicating that the consumers' usage of nutrition labels is still limited. Most respondents $(277,69.25 \%)$ reported that the information of mandatory nutrition labels is useful.

\section{Econometric Model and Results}

\subsection{Econometric Model}

It is very difficult to determine whether consumers consider the mandatory nutrition labels as useful, although we are certain that experience plays a role. Meanwhile, consumers who use nutrition labels tend to feel benefited from the labels. These two tendencies are caused by the fact that the information of nutrition labels reduces consumers' uncertainty about food quality. We assume that the usage frequency of nutrition labels is positively and significantly related to the perceived benefits of consumption. Consumers' perception of nutrition labels and their usage of the labels will explain whether they consider the mandatory nutrition labels useful. In addition, different personal and social characteristics may also influence purchase behaviors

Based on Gracia et al. (2006), this paper estimates three equations which constitute a multiple limit dependent variable model, and each equation is constructed to explain consumers' perceived benefits from mandatory nutrition labels, their usage of and their perception of nutrition labels.

Consumers' perceived benefits from mandatory nutrition labels are defined by the following equation:

$$
B_{i}^{*}=\lambda L U_{i}^{*}+\beta X_{i}+u_{i},
$$

where $L U_{\mathrm{i}}^{*}$ represents whether consumers will use nutrition labels when purchasing food, $X_{\mathrm{i}}$ represents all the exogenous variables. $u_{i}$ is the error term which follows a normal distribution of $N\left(0, \sigma_{\mathrm{u}}^{2}\right) . B_{\mathrm{i}}^{*}$ is the unobservable utility variable which indicates whether consumers perceive benefits associated with the mandatory nutrition labels. The value of $B_{\mathrm{i}}^{*}$ is presented as:

$$
\left\{\begin{array}{l}
B_{i}=1, \text { if } B_{i}>0 \\
B_{i}=0, \text { if } B_{i} \leqslant 0 .
\end{array}\right.
$$

The equation of consumers' usage of nutrition labels is: 


$$
L U_{i}^{*}=\delta K_{i}^{*}+\alpha Z_{i}+e_{i},
$$

where $K_{\mathrm{i}}^{*}$ indicates consumers' perception of nutrition labels. $Z_{\mathrm{i}}$ denotes all the exogenous variables. $e_{i}$ is the error term which follows a normal distribution of $N\left(0, \mathrm{~s}_{\mathrm{e}}^{2}\right), L U_{\mathrm{i}}^{*}$ represents the unobservable utility which indicates whether consumers will use or consult the nutrition labels when purchasing food. The value of $L U_{\mathrm{i}}^{*}$ is presented as:

$$
\left\{\begin{array}{l}
L U_{i}^{*}=1, \text { if } L U_{i}^{*}>0, \\
L U_{i}^{*}=0, \text { if } L U_{i}^{*} \leqslant 0 .
\end{array}\right.
$$

In the end, the equation of consumers' perception level is defined as:

$$
K=\varpi Y+\xi .
$$

In Equation (9), $Y_{\mathrm{i}}$ represents all the exogenous variables. $\xi_{\mathrm{i}}$ is the error term which follows a normal distribution of $N\left(0, \sigma_{\xi}^{2}\right) . K_{\mathrm{i}}^{*}$ is the unobservable utility as well as a ordinal variable. It represents consumers' perception level of nutrition labels and it could be expressed as follows:

$$
\left\{\begin{array}{l}
K_{i}=1, \text { if } K_{i} \leqslant \mu_{1}(=0), \\
K_{i}=2, \text { if } \mu_{1}<K_{i} \leqslant \mu_{2}, \\
K_{i}=3, \text { if } \mu_{2}<K_{i} \leqslant \mu_{3}, \\
\cdots \\
K_{i}=J, \text { if } \mu_{j-1} \leqslant K_{i},
\end{array}\right.
$$

where $\mu_{i}$ is an unknown initial parameter for estimating $\varpi$. The first initial parameter equals to $0\left(\mu_{1}=0\right)$.

Equation (5), (7) and (9) are estimated simultaneously. Based on the independent variables and dependent variables in these three equations, the endogenous (dependent) variables in one equation are the exogenous (independent) variables in another equation. As a result, these three equations are combined to form a multiple limit dependent variable model. In this model, $u_{i}$, $e_{i}$, and $\xi_{\mathrm{i}}$, the error terms in three equations, follow a multiple normal distribution with a mean of 0 and a variance or covariance of matrix $\Omega$. To better carry out the spatial numerical integral, it is effective to first check whether the error terms in the three equations are correlated when evaluating the multiple limit dependent variable model. If the error terms are correlated with each other, the model will be invalid. This paper will use Monte Carlo integral on the basis of the calculation procedure proposed by Hajivassiliou and McFadden (1998).

The theoretical model of the relationships between endogenous (dependent) variables and exogenous (independent) variables in Equation (5), (7) and (9) is 
presented in Fig. 1 below.

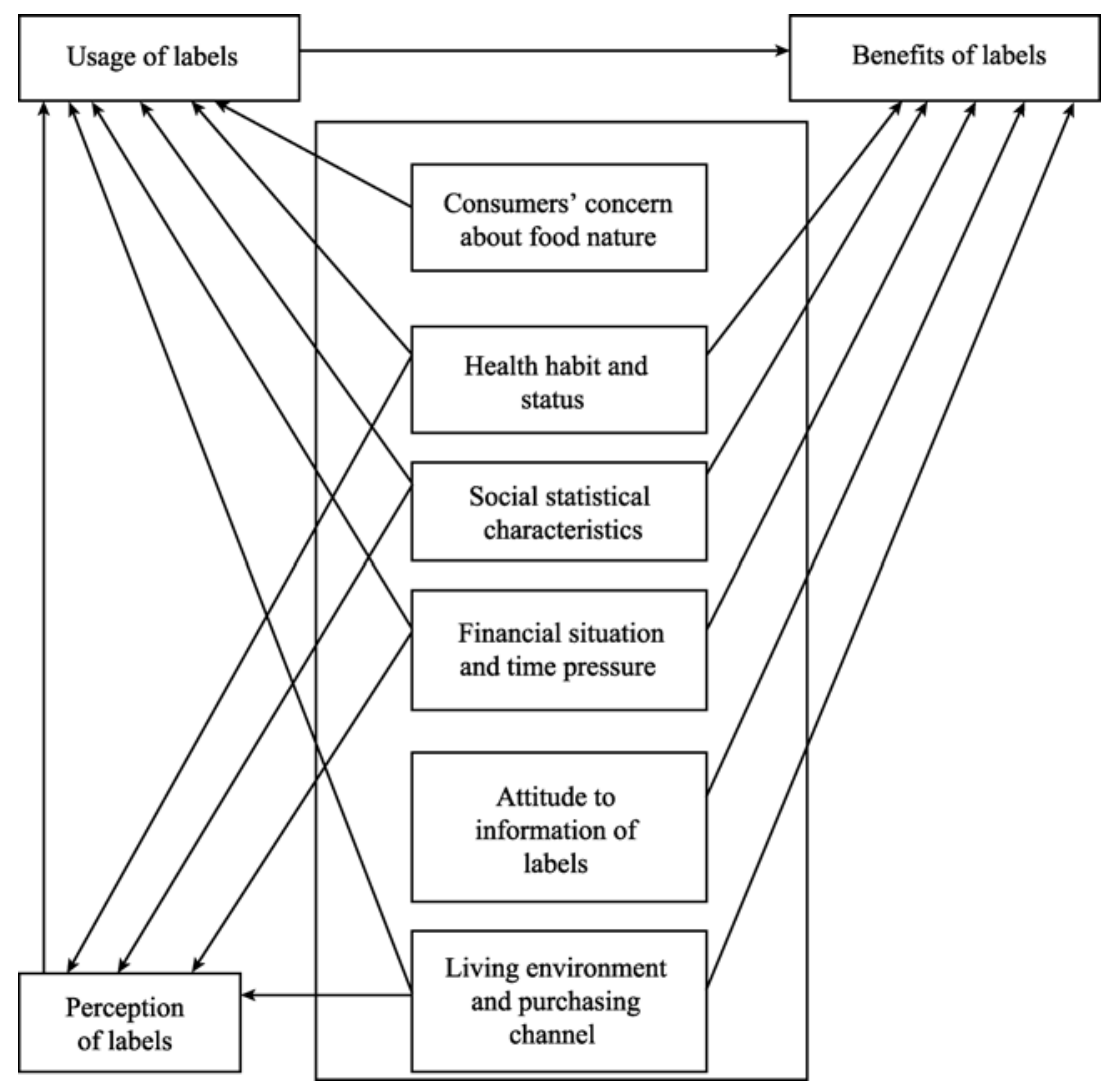

Fig. 1 Empirical Model

The endogenous variables in this paper are discrete variables. Consumers' perceived benefits from the mandatory nutrition labels form a dummy variable $(0,1)$ with 1 if consumers perceive benefits from the labels and 0 otherwise. Consumers' usage of nutrition labels is also dummy variable with 1 if consumers use the information presented in the labels or 0 otherwise. Finally, as an ordinal variable, consumers' perceived importance of nutrition labels is divided into five levels, with 1 the lowest and 5 the highest.

Gender, age, education are selected as independent variables. Due to the fact that female consumers will be more careful than male consumers in making purchase decisions, we expect that female consumers make more use of the labels. We also expect that consumers with higher education are expected to have a better understanding of the labels and make more use of them.

To measure consumers' financial situation and time pressure when purchasing 
food, average household monthly food expenditure and household size are used. Health status of consumers is expected to influence their perception and usage of nutrition labels. If consumers find their health problems are related with their diet, they will be likely to search for relevant nutritional knowledge. Therefore, health habit and health status are expected to positively affect consumers' perception and usage of nutrition labels. In addition, the model also includes consumers' frequency of physical exercises as an explanatory variable. Those who have a better health status are expected to have a higher usage of nutrition labels.

Consumers' usage of nutrition labels will be affected by their concerns about different kinds of information during purchase. Several variables are selected, such as price, quantitative information, expiration date, nutritional composition of rice, quality and safety. It is expected that the higher the consumers are concerned about price and quantitative information, the lower the probability the consumers use the nutrition labels. In contrast, if consumers pay more attention to expiration date, nutritional composition and information of quality and safety, they will tend to make more use of nutrition labels.

\subsection{Results}

Based on the simulative estimation method proposed by Hajivassiliou and McFadden (1998), the independent variables listed in Table 6 are used to evaluate the multiple limit dependent variable model of Equation (5), (7) and (9). By applying the procedure of maximum likelihood estimate, all the parameter results are presented in Table 7 .

Table 6 Variable Definitions

\begin{tabular}{|c|c|c|}
\hline Variable & Value range & Meanings of the value \\
\hline \multicolumn{3}{|c|}{ Social statistical characteristics } \\
\hline Gender & $0-1$ & Female $=1$, Male $=0$ \\
\hline Age & $1-3$ & $<30=1,31-50=2,>50=3$ \\
\hline $\begin{array}{l}\text { Educational } \\
\text { experience }\end{array}$ & $1-4$ & $\begin{array}{l}\text { Primary school and below }=1 \text {, Junior and senior middle } \\
\text { school }=2 \text {, College and undergraduate school }=3 \text {, Graduate } \\
\text { school and above }=4\end{array}$ \\
\hline \multicolumn{3}{|c|}{ Financial situation and time pressure } \\
\hline $\begin{array}{l}\text { Average monthly } \\
\text { Expenditure on } \\
\text { food (family) }\end{array}$ & $1-3$ & $<1000=1,1000-1999=2,>2000=3$ \\
\hline Family size & $\begin{array}{c}\text { Continuous } \\
\text { variables }\end{array}$ & \\
\hline \multicolumn{3}{|c|}{ Health habit and health status } \\
\hline Physical exercises & $0-1$ & Participate $=1$, Do not participate $=0$ \\
\hline
\end{tabular}


(Continued)

\begin{tabular}{|c|c|c|}
\hline Variable & Value range & Meanings of the value \\
\hline Health status & $1-5$ & Very bad $=1, \mathrm{Bad}=2$, Normal $=3$, Good $=4$, Excellent $=5$ \\
\hline $\begin{array}{l}\text { The relation } \\
\text { between health } \\
\text { problem and diet }\end{array}$ & $0-1$ & Relevant $=1$, Irrelevant $=0$ \\
\hline \multicolumn{3}{|c|}{ Concern about kinds of information } \\
\hline Price & $1-5$ & Weakest (1)-Strongest (5) \\
\hline $\begin{array}{l}\text { Quantitative } \\
\text { information }\end{array}$ & $1-5$ & Weakest (1)-Strongest (5) \\
\hline Guarantee period & $1-5$ & Weakest (1)-Strongest (5) \\
\hline $\begin{array}{l}\text { Nutritional } \\
\text { composition }\end{array}$ & $1-5$ & Weakest (1)-Strongest (5) \\
\hline $\begin{array}{l}\text { Information of } \\
\text { quality and safety }\end{array}$ & $1-5$ & Weakest (1)-Strongest (5) \\
\hline \multicolumn{3}{|c|}{ Attitude to nutrition labels } \\
\hline $\begin{array}{l}\text { Number of } \\
\text { messages in } \\
\text { nutrition labels } \\
\text { accepted by } \\
\text { consumers }\end{array}$ & $\begin{array}{c}\text { Continuous } \\
\text { variables }\end{array}$ & \\
\hline \multicolumn{3}{|c|}{ Living environment and purchase channel } \\
\hline Living environment & $0-1$ & Inside the city $=1$, Outside the city $=0$ \\
\hline Purchasing channel & $0-1$ & Supermarket $=1$, Others $=0$ \\
\hline \multicolumn{3}{|l|}{ Dependent variables } \\
\hline Perception level & $1-5$ & Very bad $=1, \mathrm{Bad}=2$, Normal $=3$, Good $=4$, Excellent $=5$ \\
\hline Usage of labels & $0-1$ & Use $=1$, Do not use $=0$ \\
\hline $\begin{array}{l}\text { Whether perceiving } \\
\text { benefits from the } \\
\text { labels }\end{array}$ & $0-1$ & Gain $=1$, Do not gain $=0$ \\
\hline
\end{tabular}

Table 7 Regression Results of Model Parameters

\begin{tabular}{|c|c|c|c|c|c|c|}
\hline \multirow{2}{*}{ Independent variables } & \multicolumn{2}{|c|}{ Perception level } & \multicolumn{2}{|c|}{ Usage of labels } & \multicolumn{2}{|c|}{ Perceived benefits } \\
\hline & Coefficient & $z$-value & Coefficient & $z$-value & Coefficient & $z$-value \\
\hline Gender & -0.24 & -1.51 & -0.12 & -0.55 & 4.81 & $4.22^{* * *}$ \\
\hline Age & 0.10 & 0.71 & -0.25 & $-1.66^{*}$ & -0.35 & -0.97 \\
\hline $\begin{array}{l}\text { Educational } \\
\text { experience }\end{array}$ & 2.94 & $14.67^{* * *}$ & 1.15 & $5.33^{* * *}$ & 4.53 & $4.63^{* * *}$ \\
\hline Current address & 0.29 & $2.16^{* *}$ & 0.03 & 0.24 & - & - \\
\hline Purchase channel & - & - & - & - & -0.12 & -0.34 \\
\hline $\begin{array}{l}\text { Average monthly } \\
\text { expenditure on food } \\
\text { (family) }\end{array}$ & 0.51 & $4.20^{* * *}$ & -0.16 & -1.23 & -0.37 & -1.13 \\
\hline
\end{tabular}


(Continued)

\begin{tabular}{|c|c|c|c|c|c|c|}
\hline \multirow{2}{*}{ Independent variables } & \multicolumn{2}{|c|}{ Perception level } & \multicolumn{2}{|c|}{ Usage of labels } & \multicolumn{2}{|c|}{ Perceived benefits } \\
\hline & Coefficient & $z$-value & Coefficient & $z$-value & Coefficient & $z$-value \\
\hline Family size & -0.12 & -1.11 & -0.44 & $-4.00^{* * *}$ & -0.74 & $-2.74^{* * *}$ \\
\hline Health status & 0.20 & $1.97^{* *}$ & -0.19 & $-1.88^{*}$ & -0.79 & $-3.30^{* * *}$ \\
\hline Physical exercises & -0.08 & -0.29 & 0.03 & 0.11 & 0.43 & $2.68^{* * *}$ \\
\hline Health awareness & 0.02 & -0.11 & 0.51 & $2.27^{* *}$ & 0.46 & 1.10 \\
\hline $\begin{array}{l}\text { Concern about food } \\
\text { quantity }\end{array}$ & - & - & -0.24 & $-2.80^{* * *}$ & - & - \\
\hline $\begin{array}{l}\text { Concern about food } \\
\text { price }\end{array}$ & - & - & -0.13 & $-1.97^{* *}$ & - & - \\
\hline $\begin{array}{l}\text { Concern about food } \\
\text { quality and safety }\end{array}$ & - & - & -0.07 & -0.96 & - & - \\
\hline $\begin{array}{l}\text { Concern about } \\
\text { guarantee period }\end{array}$ & - & - & 0.23 & $2.82^{* * *}$ & - & - \\
\hline $\begin{array}{l}\text { Concern about } \\
\text { nutritional } \\
\text { composition }\end{array}$ & - & - & 0.13 & $1.75^{*}$ & - & - \\
\hline $\begin{array}{l}\text { Number of messages } \\
\text { in labels }\end{array}$ & - & - & - & - & -0.33 & $-2.55^{* *}$ \\
\hline Perception level & - & - & 0.94 & $6.82^{* * *}$ & - & - \\
\hline Usage of labels & - & - & - & - & 0.84 & $2.86^{* * *}$ \\
\hline Sample size & 400 & & & & & \\
\hline $\begin{array}{l}\text { Maximum likelihood } \\
\text { value }\end{array}$ & -587 & & & & & \\
\hline$\mu_{2}$ & 2.93 & 11.56 & - & - & - & - \\
\hline$\mu_{3}$ & 3.89 & 14.81 & - & - & - & - \\
\hline$\mu_{4}$ & 5.13 & 18.18 & - & - & - & - \\
\hline \multicolumn{7}{|c|}{ Correlation of perception level, usage of labels and perceived benefits } \\
\hline Perception level & - & - & -0.65 & -5.21 & 0.02 & 0.15 \\
\hline Usage of labels & - & - & - & - & 0.58 & 3.15 \\
\hline
\end{tabular}

Note: *,**, and $* * *$ represent significant at $10 \%, 5 \%$, and $1 \%$ levels, respectively.

The correlation tests of error terms in the three equations are conducted. It indicates that Equation (5) and (7) are significant at 5\% significance level, Equation (7) and (9) at 5\% significance level and Equation (5) and (9) at 10\% significance level. Hence, three error terms are not correlated with each other which suggests a satisfactory goodness-of-fit of our model.

In the equation of perception level of nutrition labels, current address and health status appear to be significant at 5\% significance level while education experience and family average monthly food expenditure are significant at $1 \%$ 
significance level. All significant variables have positive effects on perception level. As expected, both educational experience and health status have a positive and significant influence on consumers' perception level of nutrition labels. Consumers with better education will consider nutrition labels as more important, and consumers with better health status pay more attention to diet quality and safety than consumers who are not in good health situation. Consumers living inside the city will have higher perception level than those living in the suburbs. Family average monthly food expenditure is positively related to the perception level of nutrition labels and those consumers with better incomes will concern more about nutrition labels for information of food quality, so that they could be able to choose high-quality food.

From the equation of nutrition labels' usage, we found that the perception level of nutrition labels has a significant and positive effect on the usage of the labels. Age has a negative influence on consumers' usage of the labels which suggests the probability of using the labels is lower if the consumers are older. Consistent with the relationship of education experience and consumers' perception of nutrition labels, consumers' usage of the labels is significantly and positively affected by education experience. As a representation of time pressure, family size appears to be statistically significant and negatively affect the usage of label. It implies that consumers with larger family size are less likely to use nutritional labels. Health status was found to be negatively related to the usage of nutrition label (significant at 10\%), partly because consumers tend to care more about diet quality and safety when they are experiencing health problems. Consumers' concern about food quantity, price, expiration and nutritional composition all significantly affect labeling usage.

Gender, educational experience, family size, health status, physical exercises and number of messages in nutrition labels are significant in changing the usage of labels.

In sum, consumers making more use of nutrition labels tend to feel beneficial from mandatory nutrition labels and the higher the consumers' education level is, the more their perceive benefits, partly because people with higher education accept new things more easily, thus pay more attention to nutritional labels. Also consumers who exercise more will perceive more benefits from the labels. Family size reflects the time pressure of consumers' families. The heavier the time pressure (the larger the family size is), the less likely consumers use nutrition labels, and the lower the probability that consumers perceive benefits from the labels. Consumers in good health conditions tend to perceive fewer benefits from the labels than that of the consumers in poorer health conditions. In addition, we also found that nutrition labels could convey appropriate and useful information to consumers only if the number of messages contained in the labels is moderate. 


\section{Conclusion}

This paper empirically analyzes Beijing consumers' rice consumption behavior to understand whether Chinese consumers benefit from the mandatory nutrition labels when purchasing rice, the most important staple food in China. Our findings show that Chinese consumers do not use the labels often. However, this infrequent use of labels is not caused by unwillingness to use the label, rather, because the label itself is difficult to use. Chinese consumers have realized the importance of nutrition labels but they have difficulties in accurately understanding the labels. This may be caused by the lack of governmental promotion or consumers' own educational level. No matter which reason is behind, it prevents consumers from precisely receiving information and lowering their ability to use the labels. Our sample indicates that consumers believe that they could benefit from nutrition labels and the policy behind the reinforcement of the labels, i.e., the enactment of Food Nutritional Labeling Management Practice. It indicates that although consumers' understanding of nutrition labels is still limited, they have kept high expectations for the reinforcement of the labels, given the expected benefits they could receive.

Key factors behind consumers' perception of nutrition labels include education, access to supermarket, monthly expenditure on food, and health status. These factors all have significant effects on consumers' perception. The variables like perception level of nutrition labels, age, educational experience, family size, health awareness, concern about food quantity, concern about food price, concern about guarantee period and nutritional composition of food are confirmed to have a significant influence on the usage of nutrition labels. Among these variables, positive influencing factors are perception level of nutrition labels, education experience, health awareness, concern about guarantee period and concern about nutritional composition, and negative influencing factors are age, family size, concern about food quantity and price.

Finally, consumers' perceived benefits from nutrition labels are affected by their usage of nutrition labels, gender, education experience, family size, health status, physical exercises and the number of messages in labels. Usage of the labels, gender, education experience and physical exercises positively influence consumers' perceived benefits while other three variables negatively affect consumers' perceived benefits.

Acknowledgements The authors are grateful to Yi Zhong, Lihua Dai and Yang Jiao for their assistance in data collection, descriptive and econometric analysis, and constructive suggestions. This paper is supported by the Fundamental Research Funds for the Central Universities, and the Research Funds of Renmin University of China (Minde Scholar Planning Project, No.20070003888), and the National Natural Science Foundation of China (No. $70773115)$. 


\section{References}

Barreiro, H. J., Gracia, A., \& de-Magistris, T. 2008. When more is less: The effect of multiple health and nutrition labels in food product choice. European Association of Agricultural Economists, International Congress Paper, 44013.

Bush, L.M., \& Williams, R.A. 1999. Diet and health: New problems/new solutions. Food Policy, 24(2): 135-144.

Cranfield, J. A. L., \& Magnusson, E. 2003. Canadian consumers' willingness to pay for pesticide free food products: An ordered probit analysis. International Food and Agribusiness Management Review, 6(4): 114-126.

Chang, H., \& Kinnucan, H. W. 1991. Advertising, information, and product quality: The case of butter. American Journal of Agricultural Economics, 73(4): 1195-1203.

Gracia, A., Loureiro, M., \& Nayga Jr., R. M. 2007. Do consumers perceive benefits from the implementation of an EU mandatory nutrition labeling program. Food Policy, 32(2): $160-174$

Gila, J. M., Gracia, A., \& Sanchez, M. 2000. Market segmentation and willingness to pay for organic products in Spain. International Food and Agribusiness Management Review, 3(1): 207-226.

Ippolito, P. M., \& Mathios, A. D. 1990. Information, advertising and health choice. Rand Journal Economics, 21(3): 59-80.

Kinnucan, H. W., \& Venkateswaran, M. 1990. Effects of generic advertising on perceptions and behavior: The case of catfish. Southern Journal of Agricultural Economics, 22(2): 137-151.

Kim, S. Y., Nayga Jr., R. M., \& Capps Jr., O. 2001. Health knowledge and consumer use of nutrition labels: The issue revisited. Agricultural and Resource Economics Review, 30(1): $10-19$.

Kim, S. Y., Nayga Jr., R. M., \& Capps Jr., O. 2001. Food label use, self-selectivity, and diet quality. The Journal of Consumer Affairs, 35(2): 346-363.

Matsumoto, S. 2004. Consumers' responses to front vs. back package GM labels in Japan. Journal of Agricultural \& Food Industrial Organization, 2(5): 1-25

Moreau, C. P., Markman, A. B., \& Lehmann, D. R. 2001. "What is it?" categorization flexibility and consumers' responses to really new products. Journal of Consumer Research, 27(4): 489-498.

Nayga Jr., R. M. 1996. Determinants of consumer' use of nutritional information on food packages. Journal of Agricultural and Applied Economics, 28(2): 303-312.

Nayga Jr., R. M. 1997. Impact of socio-demographic factors on perceived importance of nutrition in food shopping. Journal of Consumer Affairs, 31(1): 1-9.

Nayga, Jr. R. M. 2000. Nutrition knowledge, gender, and food label use. The Journal of Consumer Affairs, 34(1): 97-112.

Piedra, M. A., Schupp, A., \& Montgomery, D. 1996. Consumer use of nutrition labels on package meats. Journal of Food Distribution and Research, 27(2): 42-47.

Roe, B., \& Teisl, M. 2007. Genetically modified food labeling: The impacts of message and messenger on consumer perceptions of labels and products. Food Policy, 32(1): 49-60.

Siegrist, M., 2000. The influence of trust and perceptions of risks and benefits on the acceptance of gene technology. Risk Analysis, 20(2): 195-203.

Soregarol, C., Boccalett, S., \& Moro, D. 2003. Consumer's attitude towards labeled and unlabeled gm food products in Italy. International Food and Agribusiness Management Review, 6(2): 112-127. 
Swartz, D. G., \& Strand Jr., I. E. 1981. Avoidance costs associated with imperfect information: The case of kepone. Land Economics, 57(2): 139-150.

Sedjo, R. A., \& Swallow, S. K. 2002. Voluntary eco-labeling and the price premium. Land Economics, 78(2): 272-284.

Teisl, M. F., Boksteal, N. E., \& Levy, A. 2003. Measuring the welfare effects of nutrition information. American Journal of Agricultural Economics, 83(1): 133-149.

Vassilis A. H., \& McFadden D. L.. 1998. The method of simulated scores for the estimation of LDV models. Econometrica, Econometric Society, 66(4): 863-896.

Wang, G., Fletcher, S. M., \& Carley D. H. 1995. Consumer utilization of food labeling as a source of nutrition information. The Journal of Consumer Affairs, 29(2): 368-380.

$\mathrm{Wu}$, J., \& Fu, G. 2007. The effects of brand origin country and made-in country on consumers' product evaluations and purchase intention. Frontiers of Business Research in China, 1(3): 333-350.

Yang, D. F., \& Wang, X. X. 2010. The effects of 2-tier store brands' perceived quality, perceived quality, perceived value, brand knowledge, and attitude on store loyalty. Frontiers of Business Research in China, 4(1): 1-28.

Zeng, Y. 曾寅初. Liu, Y. 刘媛媛. \& Yu, X. 于晓华. 2008. 分层模型在食品安全支付意愿 研究中的应用一以北京市消费者对月饼添加剂支付意愿的调查为例 (Application of hierarchical model in willingness to pay for food safety: Consumer survey of willingness to pay for mooncake additive). 农业技术经济 (Journal of Agrotechnical Economics), (1): 84-90.

Zhou, Li. 周立. 2009. 中国食品安全走到十字路口 (Food safety at a crossroad). 中外对话 (China Dialogue). Retrieved April 22, 2009, from http://www.chinadialogue.net/article/ show/single/en/2945 